OPEN ACCESS

Edited by:

Sharon Rose Hill,

Swedish University of Agricultural

Sciences, Sweden

Reviewed by: Ezio Peri,

University of Palermo, Italy

Marcelo Gustavo Lorenzo, Oswaldo Cruz Foundation, Brazil

*Correspondence:

Richard D. Newcomb richard.newcomb@plantandfood.co.nz

Specialty section:

This article was submitted to

Chemical Ecology

a section of the journal

Frontiers in Ecology and Evolution

Received: 30 November 2016 Accepted: 27 January 2017

Published: 13 February 2017

Citation:

Andersson MN and Newcomb RD (2017) Pest Control Compounds Targeting Insect Chemoreceptors:

Another Silent Spring? Front. Ecol. Evol. 5:5.

doi: 10.3389/fevo.2017.00005

\section{Pest Control Compounds Targeting Insect Chemoreceptors: Another Silent Spring?}

\author{
Martin N. Andersson ${ }^{1}$ and Richard D. Newcomb ${ }^{2,3 *}$ \\ ${ }^{1}$ Department of Biology, Lund University, Lund, Sweden, ${ }^{2}$ New Zealand Institute for Plant and Food Research, Auckland, \\ New Zealand, ${ }^{3}$ School of Biological Sciences, University of Auckland, Auckland, New Zealand
}

An emerging concept in the ongoing battle against insect pests is that compounds that influence the behavior of insects by modulating their ability to smell could be developed by targeting their chemoreceptors. This idea was identified by the annual horizon scan of global conservation issues as a topic of concern for their 2015 report. Unfortunately, the publication could only afford a short discussion of the pros and cons of the approach. Here we review the concept and discuss how it might be best implemented to avoid potential off-target effects and environmental harm. We describe the first of this class of compounds, VUAA1, outlining that its highly broad range of potential insect targets would lead to many of the issues associated with broad-spectrum insecticides. We also review compounds and approaches targeting the relatively less conserved carbon dioxide receptor complex and finally highly tuned receptors to conclude that focusing on species-specific pheromone receptors would result in fewer potential off-target effects.

\section{Keywords: insect chemoreceptor, VUAA1, Off-target effects}

\section{INTRODUCTION}

Applied ecologists are always on the lookout for new ways of managing insect pests of agriculture and vectors of disease. The decline of bee populations, in part through the use of the more recently employed neonicotinoid insecticides (Kessler et al., 2015; Rundlöf et al., 2015), and the rapid uncontrolled spread of Zika virus by mosquitoes (Bogoch et al., 2016), highlight that this high stakes battle continues to rage on, with the bee example reminding us of the need to minimize nontarget impacts of pesticides. An emerging new concept in this battle against insect pests and vectors is the idea that compounds that influence the behavior of insects by modulating their ability to smell could be developed by targeting their chemoreceptors. This could be achieved through either screening with a large number of natural and synthetic compounds or eventually by structureguided design, in much the same way as many pharmaceutical drugs are developed. This idea was recently highlighted by the annual horizon scan of global conservation issues as a topic of concern for the year (Sutherland et al., 2015). Unfortunately, the publication could only afford a paragraph of little over 200 words to discuss the pros and cons of the approach and focused mainly on compounds targeting a conserved element of the insect odorant receptor complex. However, we believe the topic warrants more in depth discussion and our objective here is to review the origins of the field and discuss how the approach might be best pursued, highlighting both possible advantages and relevant environmental concerns. 


\section{TARGETING THE GENERAL INSECT SENSE OF SMELL}

Olfaction is an important sense for insects, used for everything from finding food, potential mates and oviposition sites through to evading predators and harmful microbes. The use of olfaction is taken to an extreme within the Hymenoptera, where complex chemical cues have become a "language" that binds social structure (Ayasse et al., 2001). In insects, olfaction is mediated largely by an expansive family of dedicated odorant receptors (ORs). These receptors form complexes with the obligate coreceptor Orco expressed within olfactory sensory neurons inside sensilla located mainly on the insect antennae. The conventional ligand-binding ORs provide specificity for different odorants, whereas the co-receptor forms an ion channel that is crucial for triggering the neuronal signal (reviewed in Carraher et al., 2015). Thus, Orco is present in all olfactory sensory neurons that express an odor-binding OR. Whereas, the odor-binding ORs are highly divergent across insects, both in terms of protein sequence and odor specificity, Orco is evolutionary conserved and, therefore, likely has the same function across insects (see Hansson and Stensmyr, 2011, and Andersson et al., 2015 for reviews). The identification of ORs from the genomes and transcriptomes of insect species and the recent development of high-throughput cell-based assays allowing OR screening with thousands of ligands have facilitated the development of an efficient pharmacological approach to identify agonists and antagonists for these receptors. One of the first of these studies was conducted against receptors from the malaria mosquito, Anopheles gambiae, leading to the identification of the synthetic compound VUAA1 ( $N$-(4-ethylphenyl)-2-((4-ethyl-5(3-pyridinyl)-4H-1,2,4-triazol-3-yl)thio)acetamide) as an agonist for the co-receptor Orco itself (Jones et al., 2011). This compound is able to activate Orco to stimulate ion channel opening, even in the absence of odor-binding ORs or their odorants. Not only is VUAA1 active on the Orco of A. gambiae, but also on Orcos from other species, including other dipterans (but see Andersson et al., 2016 for an exception in Diptera), lepidopterans, and hymenopterans, raising the possibility that agonists (such as VUAA1) and antagonists of Orco might be able to impact olfaction in species from many insect orders. The discovery of VUAA1 sparked interest in using Orco modulators as broadly active insect repellents that could be used to fight both disease vectors and agricultural pests (Jones et al., 2011). A major issue with the efficacy of VUAA1, however, is that the molecule is not particularly volatile, rendering it largely impotent for insect control. There has therefore been a concerted effort to identify other modulators of Orco, with additional agonists (Chen and Luetje, 2012; Taylor et al., 2012; Romaine et al., 2014), and antagonists (Chen and Luetje, 2012, 2013; Jones et al., 2012; Pask et al., 2013; Bobkov et al., 2014) now described, with some displaying higher potency and/or volatility than VUAA1. In contrast to the Orco agonists that interfere with odor-guided behaviors by over-stimulating insect olfaction, the antagonists, in principle, would render insects anosmic, preventing any communication via odorants. However, whether Orco is activated or inhibited, the negative impact on the insect sense of smell, and thus behavior, may well be similar. Additionally, Orco has been shown to be present in the testes and spermatozoa of insects, with Orco agonists and antagonists affecting flagella beating and thus the movement of mosquito spermatozoa (Pitts et al., 2014). These compounds might therefore also directly and broadly interfere with insect reproduction, and by disrupting multiple aspects of the insect life cycle could potentially be very efficient in insect control.

\section{Risks of Off-Target Effects}

While broadly active disruptive compounds targeting Orco have potential commercial value, their application may arguably incur the same undesirable effects on non-target insects as broadspectrum insecticides due to the evolutionary conservation of Orco function in many insect orders. If such compounds were to be released over large areas for management of agricultural pests or in disease vector extermination programs, they would most likely affect the majority of insects in that area, as well as the targeted pest or vector species. Beneficial insects in farmland, urban, or natural ecosystems, such as honeybees or their wild relatives may likewise be impacted, affecting pollination and the ability of insect predators and parasitoids to locate prey and hosts, respectively. Effects could also potentially spread via food chains to vertebrates, such as insectivorous birds, mammals, amphibians, reptiles, and fish. The extent of these potential environmental impacts would depend on the rate of biodegradation of the compound(s) and their frequency of application in the field.

In contrast to large-scale application in modified or unmodified ecosystems, applying compounds that target Orco to smaller point sources should reduce the risk of environmental impacts. Currently, DEET ( $N, N$-diethyl-m-toluamide) is the most commonly used personal insect repellent applied to human skin. Potential receptor targets for DEET have been identified, however the mode of action for the compound and its potential receptor target(s) remain hotly debated (Ditzen et al., 2008; Syed and Leal, 2008; Lee et al., 2010; Kain et al., 2013; Enjin et al., 2016). It is possible that Orco modulators, such as VUAA1 could be used in a similar way as DEET. In fact, both VUAA1 and especially its structural analog VUAA4 have been shown to modulate mosquito behavior at lower concentrations than DEET (Taylor et al., 2012). Another possibility might be to limit the release of such compounds to human households to interfere with mosquito hut entry behaviors (Turner et al., 2011).

\section{TARGETING RECEPTORS PRESENT IN FEWER SPECIES SHOULD BE ASSOCIATED WITH LOWER ENVIRONMENTAL RISK}

While the use of compounds that act on Orco may have undesired non-target consequences (Figure 1A), there are other receptors that could be focused on for the purpose of insect control. One receptor complex that has received some attention in this context is the carbon dioxide $\left(\mathrm{CO}_{2}\right)$ receptor complex of higher insects. This receptor complex is made up by members of the 


\section{A Compounds targeting the odorant receptor co-receptor, Orco}

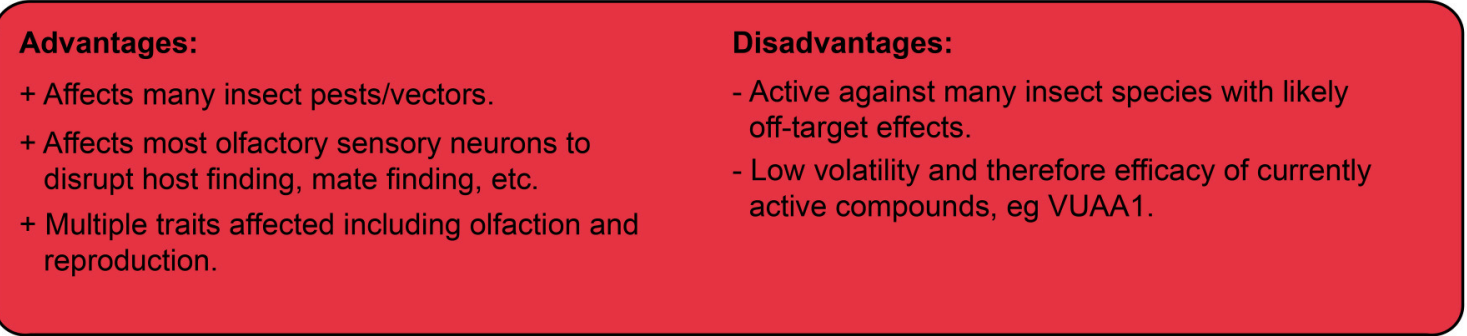

\section{B Compounds targeting the $\mathrm{CO}_{2}$ receptor complex}

Advantages:

+ Potentially useful target for fly/mosquito, beetle, and moth pests/vectors.

+ Currently active compounds are volatile.

+ Currently active compounds are generally regarded as safe.

+ Likely fewer off-target effects compared with targeting Orco

\section{Disadvantages:}

- $\mathrm{CO}_{2}$ responses unknown in most species with risks of off-target effects on flies/mosquitoes, beetles and moths.

- Affects only a component of the insect chemosensory system, therefore likely to have less impact on insect behavior compared with targeting Orco.

- Does not target reproductive behaviors.

\section{c Compounds targeting sex-/aggregation pheromone receptors}

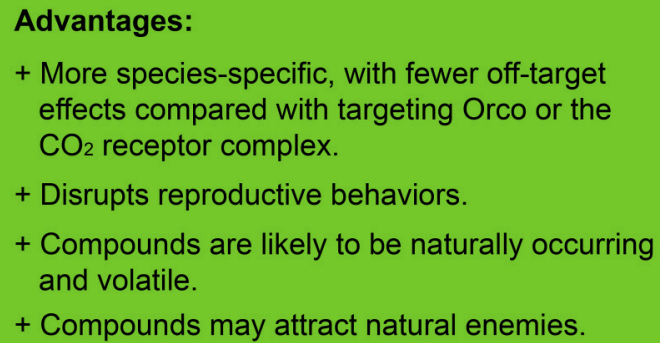

Disadvantages:

- Different compounds required for each pest/vector.

- Not all insect species use such pheromones.

Pheromones and their receptors not identified in many species.

FIGURE 1 | Summary of the possible advantages and disadvantages/environmental risks of using compounds targeting (A) the evolutionary conserved insect odorant receptor co-receptor (Orco), (B) the relatively less conserved insect carbon dioxide receptor complex, and (C) more species-specific receptors for sexor aggregation pheromones, in pest- or disease vector control.

gustatory receptor (GR) family, especially GR1 and GR3, and has been retained over evolutionary time at least among the Diptera, Coleoptera, and Lepidoptera, although additional insect taxa are also able to detect $\mathrm{CO}_{2}$ (Robertson and Kent, 2009). Thus, although this receptor complex occurs in fewer taxa than Orco, it is present among three of the major insect orders, all of which contain serious agricultural pests and disease vectors. For example, in disease-spreading mosquitoes, the detection of $\mathrm{CO}_{2}$ by this receptor complex is very important for their ability to locate human hosts. Just as for Orco, and because of its important role for host finding in mosquitoes, the $\mathrm{CO}_{2}$ receptor complex has been the target of large scale compound screenings resulting in the discovery of highly active agonists ("superagonists"), as well as antagonists (Turner and Ray, 2009; Turner et al.,
2011; Tauxe et al., 2013). In this case, however, the active ligands found to date are naturally occurring volatile compounds including e.g., cyclopentanone, ethyl pyruvate, 1-hexanol, 2,3butanedione, butanal, and pentanal (Turner and Ray, 2009; Tauxe et al., 2013). Several of these odorants show similar effects on $\mathrm{CO}_{2}$ receptors across different species of mosquitoes (i.e., the malaria vector $A$. gambiae, the West Nile vector Culex quinquefasciatus, and the Zika, chikungunya, dengue and yellow-fever vector Aedes aegypti) as well as the vinegar fly Drosophila melanogaster, and their interaction with the receptor is sufficient to interfere with $\mathrm{CO}_{2}$-mediated behaviors (Turner et al., 2011). However, 2,3-butanedione has opposing effects in drosophilid flies compared to mosquitoes, inhibiting the $\mathrm{CO}_{2}$ response in Drosophila, but eliciting ultra-prolonged activation 
of $\mathrm{CO}_{2}$ neurons in mosquitoes. This latter effect results in impaired $\mathrm{CO}_{2}$ attraction and reduction in $\mathrm{CO}_{2}$-mediated hut entry behavior of C. quinquefasciatus (Turner et al., 2011). Similar to the broadly active compounds that target Orco, the compounds that can modulate $\mathrm{CO}_{2}$-responses are also likely to affect non-target insects (Figure 1B). However, the negative side effects of targeting this receptor complex are likely to be less severe compared with targeting Orco because (i) the compounds would not activate or deactivate the entire olfactory system, (ii) fewer insect taxa possess the conserved $\mathrm{CO}_{2}$ receptor complex compared to Orco, (iii) the $\mathrm{CO}_{2}$ receptor targeting compounds identified to date are naturally occurring and some of them are generally regarded as safe (Tauxe et al., 2013). Nevertheless, because the ecological importance of $\mathrm{CO}_{2}$ is unknown in most insect species, and because the above-mentioned compounds are physiologically and/or behaviorally active in many species, the release of large quantities of such compounds may well be associated with unexpected side effects on insect and animal communities. In addition, the pest control efficacy of agonists or antagonists targeting the $\mathrm{CO}_{2}$ receptor is likely to be lower than that for compounds targeting Orco, because $\mathrm{CO}_{2}$ is commonly used by insects in combination with input from additional receptors in the host finding process.

\section{TARGETING SPECIES-SPECIFIC RECEPTORS SHOULD BE DESIRABLE FROM AN ENVIRONMENTAL PERSPECTIVE}

Another option for this approach to new insect control tactics is to target chemosensory receptors that are more species-specific. Sex pheromone receptors are such an example and also offer the advantage of being proven targets where current management techniques, such as mating disruption, are widely utilized to reduce population numbers by reducing matings. Tailoring compounds that can modulate responses of sex pheromone receptors should have significantly lower environmental risks compared to modulators of the $\mathrm{CO}_{2}$ receptor complex and especially Orco, because sex pheromone receptors generally recognize species-specific sets of compounds (Figure 1C). Several recent studies have identified natural odorants that interfere with responses to sex pheromones, at the molecular, neurophysiological, and behavioral levels. For instance, (E)-4,8-dimethyl-1,3,7-nonatriene (DMNT), a herbivore-induced plant volatile, interferes with the detection of both sex pheromone and host-derived attractants in the Egyptian cotton leaf worm, Spodoptera littoralis (Lepidoptera), reducing attraction to both sex pheromones and host attractants (Hatano et al., 2015). Because DMNT also attracts natural enemies of herbivores it might be a good target for sustainable agricultural pest control. Similarly, Pregitzer et al. (2012) showed that several plant compounds (linalool, linalyl acetate, Z3hexenol, and geraniol) interfere with sex pheromone detection in the tobacco budworm, Heliothis virescens (Lepidoptera), and that the interference occurs at the level of the receptor via competitive antagonism. A similar story is emerging for aggregation pheromones of tree-killing bark beetles, which during outbreaks can be a serious threat to forests, both planted and unmodified (Raffa et al., 2016). In the European spruce bark beetle, Ips typographus, the herbivore-induced spruce defense compound, 1,8-cineole (Schiebe et al., 2012), strongly reduces attraction to the aggregation pheromone, which is used to coordinate deadly mass-attacks on trees (Andersson et al., 2010; Binyameen et al., 2014). The sensory neuron that detects 1,8-cineole is housed within the same sensilla as that for one of the essential aggregation pheromone components, and when the 1,8-cineole neuron responds, the response to the aggregation pheromone component in the other neuron is inhibited, probably via passive electrical interactions between neurons (Andersson et al., 2010). Such neuronal cross-talk has also been demonstrated to occur in Drosophila, with significant effects on behavior (Su et al., 2012); thus it probably represents a neurophysiological mechanism widespread among insects. The potential use of compounds that interfere directly with sex/aggregation pheromone receptors or indirectly on neurophysiological responses is a promising avenue for the development of sustainable integrated pest management. It is, however, unclear whether the same expected control efficacy of compounds targeting a specific receptor will be achieved as compared with compounds targeting Orco (or the use of insecticides), especially for species that utilize multiple sensory modalities for host or mate finding. Thus, it is possible that several specific receptors will have to be targeted simultaneously to achieve sufficient control. In addition, while control measures that target sex- or aggregation pheromone receptors will likely be more species-specific, not all pest species use such pheromones, and even where they do, not all have had their chemical components or receptors identified. While this may seem like a limitation of this approach at this time, ongoing research should identify more species-specific pheromones and their chemoreceptors.

\section{CONCLUSIONS}

The potential environmental issues and unintended consequences on ecosystems of the development of insect control tactics targeting chemoreceptors have received little, if any, attention. The aim of this essay is to highlight such issues and stimulate debate amongst the scientific community and policy makers to prevent some of the same mistakes being made as associated with the widespread use of broad spectrum pesticides, especially insecticides. We suggest that control technologies targeting chemoreceptors that detect compounds which are specific for a pest should be the option of choice for a pharmacological approach to insect control using odorants. This strategy would limit the potential for non-target impacts if the compounds were used over large areas. If compounds are developed against targets, such as Orco and $\mathrm{CO}_{2}$ receptors that are evolutionary conserved and widely occurring among insects, then their use would be best reserved for personal use rather than large scale field application to minimize the risk of a "Silent Spring." So in conclusion, while we argue that there may well be 
potential risks with this approach as pointed out by the annual horizon scan of global conservation issues, we also maintain that these risks could be best mitigated by focusing on more species-specific targets and their targeted application based on their specificity.

\section{AUTHOR CONTRIBUTIONS}

All authors listed, have made substantial, direct and intellectual contribution to the work, and approved it for publication.

\section{REFERENCES}

Andersson, M. N., Corcoran, J. A., Zhang, D.-D., Hillbur, Y., Newcomb, R. D., and Löfstedt, C. (2016). A sex pheromone receptor in the Hessian fly Mayetiola destructor (Diptera, Cecidomyiidae). Front. Cell. Neurosci. 10:212. doi: 10.3389/fncel.2016.00212

Andersson, M. N., Larsson, M. C., Blaženec, M., Jakuš, R., Zhang, Q.-H., and Schlyter, F. (2010). Peripheral modulation of pheromone response by inhibitory host compound in a beetle. J. Exp. Biol. 213, 3332-3339. doi: 10.1242/jeb.0 44396

Andersson, M. N., Löfstedt, C., and Newcomb, R. D. (2015). Insect olfaction and the evolution of receptor tuning. Front. Ecol. Evol. 3:53. doi: $10.3389 /$ fevo.2015.00053

Ayasse, M., Paxton, R. J., and Tengö, J. (2001). Mating behavior and chemical communication in the order Hymenoptera. Annu. Rev. Entomol. 46, 31-78. doi: 10.1146/annurev.ento.46.1.31

Binyameen, M., Jankuvova, J., Blaženec, M., Jakuš, R., Song, L., Schlyter, F., et al. (2014). Co-localization of insect olfactory sensory cells improves the discrimination of closely separated odour sources. Funct. Ecol. 28, 1216-1223. doi: 10.1111/1365-2435.12252

Bobkov, Y., Corey, E., and Ache, B. (2014). An inhibitor of $\mathrm{Na}^{+} / \mathrm{Ca}^{2+}$ exchange blocks activation of insect olfactory receptors. Biochem. Biophys. Res. Commun. 450, 1104-1109. doi: 10.1016/j.bbrc.2014.06.120

Bogoch, I. I., Brady, O. J., Kraemer, M. U., German, M., Creatore, M. I., Kulkarni, M. A., et al. (2016). Anticipating the international spread of Zika virus from Brazil. Lancet 387, 335-336. doi: 10.1016/S0140-6736(16)00 080-5

Carraher, C., Dalziel, J., Jordan, M. D., Christie, D. L., Newcomb, R. D., and Kralicek, A. V. (2015). Towards an understanding of the structural basis for insect olfaction by odorant receptors. Insect Biochem. Mol. Biol. 66, 31-41. doi: 10.1016/j.ibmb.2015.09.010

Chen, S., and Luetje, C. W. (2012). Identification of new agonists and antagonists of the insect odorant receptor co-receptor subunit. PLOS ONE 7:e36784. doi: 10.1371/journal.pone.0036784

Chen, S., and Luetje, C. W. (2013). Phenylthiophenecarboxamide antagonists of the olfactory receptor co-receptor subunit from a mosquito. PLOS ONE 8:e84575. doi: 10.1371/journal.pone.0084575

Ditzen, M., Pellegrino, M., and Vosshall, L. B. (2008). Insect odorant receptors are molecular targets of the insect repellent DEET. Science 319, 1838-1842. doi: $10.1126 /$ science. 1153121

Enjin, A., Zaharieva, E. E., Frank, D. D., Mansourian, S., Suh, G. S., Gallio, M., et al. (2016). Humidity Sensing in Drosophila. Curr. Biol. 26, 1352-1358. doi: 10.1016/j.cub.2016.03.049

Hansson, B. S., and Stensmyr, M. C. (2011). Evolution of insect olfaction. Neuron 72, 698-711. doi: 10.1016/j.neuron.2011.11.003

Hatano, E., Saveer, A. M., Borrero-Echeverry, F., Strauch, M., Zakir, A., Bengtsson, M., et al. (2015). A herbivore-induced plant volatile interferes with host plant and mate location in moths through suppression of olfactory signalling pathways. BMC Biol. 13:75. doi: 10.1186/s12915-015-0 188-3

Jones, P. L., Pask, G. M., Rinker, D. C., and Zwiebel, L. J. (2011). Functional agonism of insect odorant receptor ion channels. Proc. Natl. Acad. Sci. U.S.A. 108, 8821-8825. doi: 10.1073/pnas.1102425108

\section{ACKNOWLEDGMENTS}

We are thankful to Caroline Isaksson, Olle Anderbrant and Marcus Stensmyr for useful critique of a previous draft of the manuscript. We also thank the Swedish Foundation for International Cooperation in Research and Higher Education (STINT) for funds supporting the collaboration between the Swedish and New Zealand investigators. MA also acknowledges funding from the Swedish Research Council FORMAS (grant 217-2014-689).

Jones, P. L., Pask, G. M., Romaine, I. M., Taylor, R. W., Reid, P. R., Waterson, A. G., et al. (2012). Allosteric antagonism of insect odorant receptor ion channels. PLoS ONE 7:e30304. doi: 10.1371/journal.pone.0030304

Kain, P., Boyle, S. M., Tharadra, S. K., Guda, T., Pham, C., Dahanukar, A., et al. (2013). Odour receptors and neurons for DEET and new insect repellents. Nature 502, 507-512. doi: 10.1038/nature12594

Kessler, S. C., Tiedeken, E. J., Simcock, K. L., Derveau, S., Mitchell, J., Softley, S., et al. (2015). Bees prefer foods containing neonicotinoid pesticides. Nature 521, 74-76. doi: 10.1038/nature14414

Lee, Y., Kim, S. H., and Montell, C. (2010). Avoiding DEET through insect gustatory receptors. Neuron 67, 555-561. doi: 10.1016/j.neuron.2010.07.006

Pask, G. M., Bobkov, Y. V., Corey, E. A., Ache, B. W., and Zwiebel, L. J. (2013). Blockade of insect odorant receptor currents by amiloride derivatives. Chem. Senses 38, 221-229. doi: 10.1093/chemse/bjs100

Pitts, R. J., Liu, C., Zhou, X., Malpartida, J. C., and Zwiebel, L. J. (2014). Odorant receptor-mediated sperm activation in disease vector mosquitoes. Proc. Natl. Acad. Sci. U.S.A. 111, 2566-2571. doi: 10.1073/pnas.13229 23111

Pregitzer, P., Schubert, M., Breer, H., Hansson, B. S., Sachse, S., and Krieger, J. (2012). Plant odorants interfere with detection of sex pheromone signals by male Heliothis virescens. Front. Cell. Neurosci. 6:42. doi: $10.3389 /$ fncel.2012.00042

Raffa, K., Andersson, M. N., and Schlyter, F. (2016). "Chapter one-Host selection by bark beetles: Playing the odds in a high-stakes game," in Advances in Insect Physiology, Vol. 50, eds C. Tittiger and G. J. Blomquist. (Oxford: Academic press), 1-74

Robertson, H. M., and Kent, L. B. (2009). Evolution of the gene lineage encoding the carbon dioxide receptor in insects. J. Insect Sci. 9, 19. doi: 10.1673/031.009.1901

Romaine, I. M., Taylor, R. W., Saidu, S. P., Kim, K., Sulikowski, G. A., Zwiebel, L. J., et al. (2014). Narrow SAR in odorant sensing Orco receptor agonists. Bioorg. Med. Chem. Lett. 24, 2613-2616. doi: 10.1016/j.bmcl.2014. 04.081

Rundlöf, M., Andersson, G. K., Bommarco, R., Fries, I., Hederström, V., Herbertsson, L., et al. (2015). Seed coating with a neonicotinoid insecticide negatively affects wild bees. Nature 521, 77-80. doi: 10.1038/nature14420

Schiebe, C., Hammerbacher, A., Birgersson, G., Witzell, J., Brodelius, P. E., Gershenzon, J., et al. (2012). Inducibility of chemical defenses in Norway spruce bark is correlated with unsuccessful mass attacks by the spruce bark beetle. Oecologia 170, 183-198. doi: 10.1007/s00442-012-2 298-8

Su, C.-Y., Menuz, K., Reisert, J., and Carlson, J. R. (2012). Non-synaptic inhibition between grouped neurons in an olfactory circuit. Nature 492, 66-71. doi: $10.1038 /$ nature 11712

Sutherland, W. J., Clout, M., Depledge, M., Dicks, L. V., Dinsdale, J., Entwistle, A. C., et al. (2015). A horizon scan of global conservation issues for 2015. Trends Ecol. Evol. 30, 17-24. doi: 10.1016/j.tree.2014.11.002

Syed, Z., and Leal, W. S. (2008). Mosquitoes smell and avoid the insect repellent DEET. PNAS 105, 13598-13603. doi: 10.1073/pnas.08053 12105

Tauxe, G. M., Macwilliam, D., Boyle, S. M., Guda, T., and Ray, A. (2013). Targeting a dual detector of skin and $\mathrm{CO}_{2}$ to modify mosquito host seeking. Cell 155, 1365-1379. doi: 10.1016/j.cell.2013.11.013 
Taylor, R. W., Romaine, I. M., Liu, C., Murthi, P., Jones, P. L., Waterson, A. G., et al. (2012). Structure-activity relationship of a broad-spectrum insect odorant receptor agonist. ACS Chem. Biol. 7, 1647-1652. doi: 10.1021/cb30 $0331 \mathrm{z}$

Turner, S. L., Li, N., Guda, T., Githure, J., Cardé, R. T., and Ray, A. (2011). Ultraprolonged activation of $\mathrm{CO}_{2}$-sensing neurons disorients mosquitoes. Nature 474, 87-91. doi: 10.1038/nature10081

Turner, S. L., and Ray, A. (2009). Modification of $\mathrm{CO}_{2}$ avoidance behaviour in Drosophila by inhibitory odorants. Nature 461, 277-281. doi: $10.1038 /$ nature08295
Conflict of Interest Statement: The authors declare that the research was conducted in the absence of any commercial or financial relationships that could be construed as a potential conflict of interest.

Copyright (c) 2017 Andersson and Newcomb. This is an open-access article distributed under the terms of the Creative Commons Attribution License (CC BY). The use, distribution or reproduction in other forums is permitted, provided the original author(s) or licensor are credited and that the original publication in this journal is cited, in accordance with accepted academic practice. No use, distribution or reproduction is permitted which does not comply with these terms. 